\title{
Distribuição de linfonodos no mesorreto - implicações na excisão total do mesorreto*
}

\author{
Distribution of lymph nodes - how deep is it \\ TME necessary?
}

\author{
Victor Edmond Seid', Rodrigo Oliva Perez', Cláudio José Caldas \\ Bresciani', Diego Daniel Pereira², Érica Helou Bresciani², \\ Bárbara Helou Bresciani²
}

\begin{abstract}
Seid VE, Perez RO, Bresciani CJC, Pereira DD, Bresciani EH, Bresciani BH. Distribuição de linfonodos no mesorreto - implicações na excisão total do mesorreto. Rev Med (São Paulo). 2007 abr.-jun.;86(2):101-5.

RESUMO: Introdução: A excisão total do mesorreto teve grande impacto na diminuição das taxas de recidiva local no câncer retal. Entretanto o número e a distribuição de linfonodos pelo mesorreto permanecem controversos. Estudos indicaram maior prevalência de linfonodos no terço posterior médio e dois terços superiores do mesorreto. Para confirmar a baixa freqüência de linfonodos distais realizamos estudo em cadáveres com maior número de corpos. Métodos: Realizamos uma excisão total do mesorreto por incisão abdominal mediana em 18 cadáveres frescos. Dividimos o mesorreto em duas porções laterais e um posterior, e definimos 3 níveis de proximal a distal. Após dissecção dos linfonodos sem solução de limpeza específica, a confirmação histológica e a determinação de localização e tamanho dos linfonodos foi realizada. Resultados: Em média, encontramos 5.0 $\pm 3.7 \mathrm{LN} /$ peça, com tamanho de $3.0 \pm 2.7 \mathrm{~mm}$. Não houve associação entre número de $\mathrm{LN}$ e tamanho com sexo, IMC ou idade. Constatamos maior prevalência de $\mathrm{LN}$ posteriores (2.8 LN/paciente) quando comparados a laterais ( 0.8 e $1.2 \mathrm{LN} /$ paciente; $p=0.02$ ). Não houve diferenças entre os níveis do reto. Conclusão: Linfonodos no tecido mesoretal são em sua maioria pequenos e de localização posterior. Não há diminuição no número de linfonodos no terço mais distal do mesorreto.
\end{abstract}

DESCRITORES: Neoplasias retais/cirurgia. Linfonodos/patologia. Adenocarcinoma. Cirurgia colorretal/métodos.

\footnotetext{
* Prêmio Oswaldo Cruz - Área Cirúrgica

${ }^{1}$ Orientador. Doutor do Departamento de gastroenterologia da FMUSP.

${ }^{2}$ Acadêmico.
}

Endereço para correspondência: Diego Daniel Pereira. Avenida Paulista, 282 ap. 41. Bela Vista - São Paulo, SP, Brasil. CEP: 01310-000. e-mail: diegodaniel@gmail.com 


\section{INTRODUÇÃO}

A excisão total do mesorreto (ETM) é uma alternativa cirúrgica para tratamento de tumores localizados nos dois terços distais do reto associada a melhores resultados e menores taxas de recidiva local ${ }^{6}$ quando comparada com a técnica convencional de dissecção cega no interior do espaço sacral.

A técnica de ETM baseia-se na dissecção e remoção por completo do mesorreto, incluindo toda a fáscia retal própria que o envolve posteriormente ${ }^{3}$. Estudos destacaram a importância da retirada intacta da fáscia retal própria, já que ela atua como um envoltório do reto e seu mesentérioº ${ }^{2}$ no qual os linfonodos peri-retais estão localizados.

As principais vantagens da técnica de ETM são a preservação de estruturas exteriores à fáscia retal própria, particularmente feixes nervosos que se dirigem para bexiga, próstata e vagina; e a remoção dos linfonodos peri-retais, que constituem a primeira área de drenagem para células metastáticas advindas do tumor de reto. Essas características associam a ETM a menores taxas de complicações pósoperatórias como disfunção urinária e sexual, e também a uma menor taxa de recidiva local, melhor sobrevida e necessidade reduzida de quimioradioterapia neoadjuvante ${ }^{5}$.

Apesar do grande uso dessa técnica e da idéia já difundida de ser a melhor abordagem cirúrgica, poucos trabalhos têm sido publicados recentemente estudando a distribuição, localização e tamanho dos linfonodos no mesorreto ${ }^{10}$.

O objetivo do presente estudo é identificar o padrão de distribuição de linfonodos no mesorreto, correlacionando sua localização, quantidade e tamanho.

\section{PACIENTES E MÉTODOS}

Realizamos a excisão total do mesorreto (ETM) através de uma incisão abdominal mediana em 18 cadáveres do Serviço de Verificação de Óbitos da Capital (SVOC), órgão vinculado ao Departamento de Anatomia Patológica da Faculdade de Medicina da Universidade de São Paulo.

Nove cadáveres eram do sexo masculino e os outros nove do sexo feminino. A idade média foi de $59.3 \pm 9.9$ anos, e o índice de massa corporal (IMC) médio foi de $25.2 \pm 3$.9. Oito pacientes possuíam IMC menor que 25, e dez IMC maior ou igual a vinte e cinco. Nenhum dos pacientes estudados possuía história prévia de câncer ou processo inflamatório na data do óbito. Não foi utilizado nenhum tipo de produto para preservação do cadáver, possibilitando que a excisão total do mesorreto fosse realizada de maneira semelhante à cirurgia.

Definimos então o ponto em que a tênia se funde como o limite superior do reto e os músculos elevadores do ânus como o limite inferior. A fáscia pré-sacral foi definida como a borda posterior de dissecção e a vagina/próstata como a borda anterior. Como limites laterais estabelecemos a borda lateral do mesorreto e as veias retais médias.

Após a ETM o reto foi aberto longitudinalmente em sua superfície anterior. O mesorreto foi dissecado e liberado do reto. As porções posterior, esquerda e direita foram marcadas para facilitar a identificação. O mesentério foi então dividido em três partes correspondentes aos terços superior, médio e inferior do reto.

Os linfonodos foram dissecados sem a utilização de soluções para facilitar sua visualização. Realizamos exames anátomo-patológicos confirmando os achados da dissecção.

A distribuição linfonodal foi então estudada radialmente nos três quadrantes do mesorreto posterior, esquerdo e direito (Figura 1); e, em cada um desses quadrantes, ela foi estudada longitudinalmente nos três segmentos correspondentes aos terços superior, médio e inferior do reto (Figura 2).

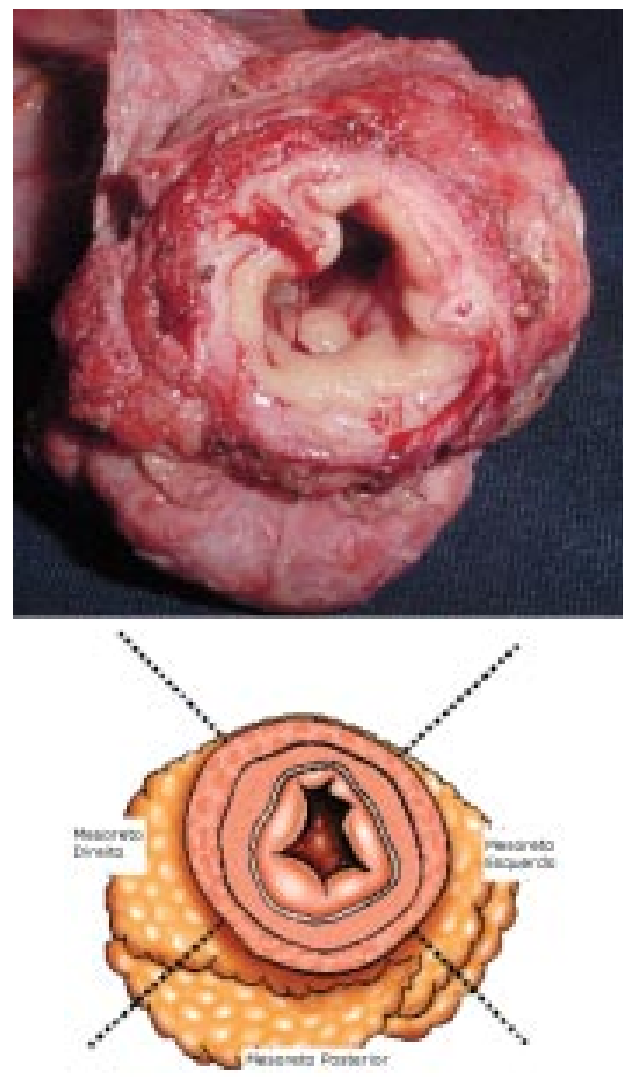

Figura 1. Disposição Radial. 


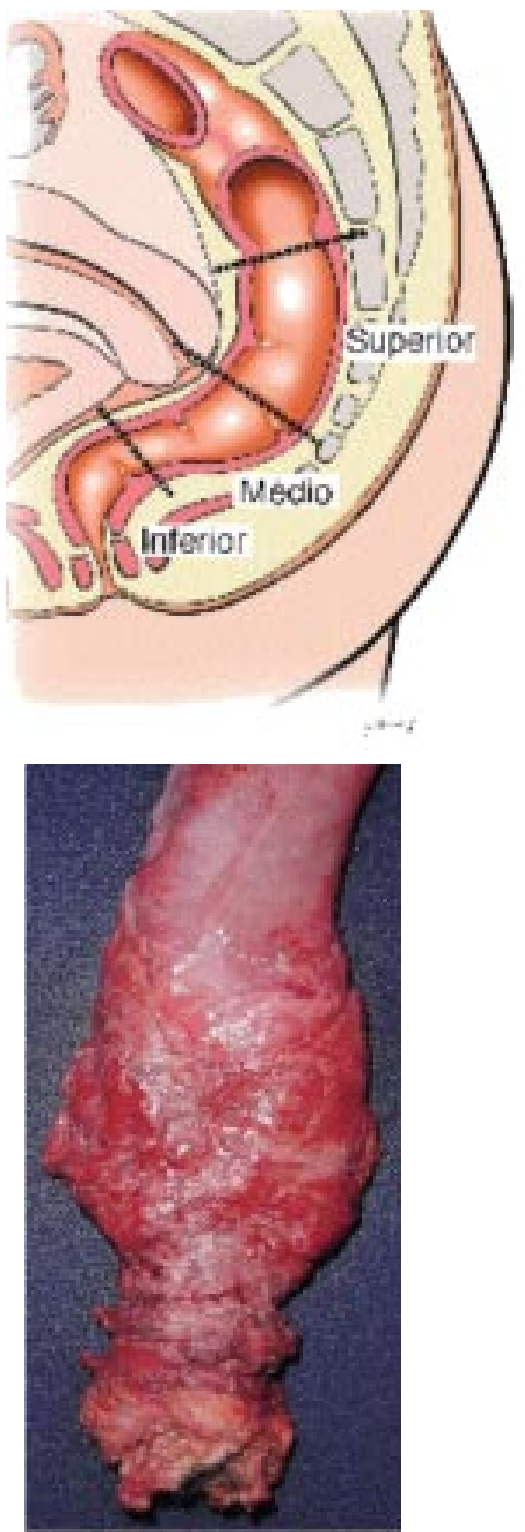

Figura 2. Disposição Longitudinal.

\section{RESULTADOS}

Após a dissecção de oito cadáveres do sexo masculino e oito do feminino encontramos uma média geral de 5.0 $\$ 3.7$ linfonodos por cadáver, com um tamanho de $3 \pm 2 \mathrm{~mm}$. Dividindo os dados por sexo encontramos uma média de $5.3 \pm 4.7$ linfonodos no sexo masculino e $4.7 \pm 2.7$ no feminino $(p=0.76)$; quanto ao tamanho dos linfonodos as médias encontradas foram de $2.8 \pm 2.5 \mathrm{~mm}$ no masculino e $3.2 \pm 1.8$ no feminino $(p=0.66)$. Não encontramos, pois, diferenças estatisticamente significantes, o que podemos melhor evidenciar através da Tabela 1.

Tabela 1. Características de acordo com sexo.

\begin{tabular}{llll}
\hline & Masculino & Feminino & $\mathbf{p}$ \\
\hline $\mathbf{N}$ & $\mathbf{9}$ & $\mathbf{9}$ & \\
\hline Idade (anos) & $60.1 \pm 11.3$ & $58.5 \pm 8.9$ & 0.75 \\
IMC $\left(\mathrm{kg} / \mathrm{m}^{2}\right)$ & $26.5 \pm 4.3$ & $24.0 \pm 3.1$ & 0.17 \\
LNs/cadaver & $5.3 \pm 4.7$ & $4.7 \pm 2.7$ & 0.76 \\
Tamanho Médio & $28 \pm 25 \mathrm{~mm}$ & $32 \pm 18 \mathrm{~mm}$ & 0.66 \\
\hline
\end{tabular}

Outra possibilidade investigada foi a existência de diferenças no número e tamanho dos linfonodos de acordo com o IMC, a qual revelou-se equivocada, já que para os dez pacientes com IMC maior ou igual a vinte e cinco encontramos $5.5 \pm 4.4$ linfonodos medindo $2.2 \pm 1.1 \mathrm{~mm}$ e para os oito pacientes com IMC menor que vinte e cinco encontramos $4.5 \pm 2.9$ linfonodos medindo $4.0 \pm 2.7 \mathrm{~mm}(p=0.59$ e $p=0.07$ para número e tamanho, respectivamente). Representamos esses resultados na Tabela 2.

Tabela 2. Características de acordo com o IMC

\begin{tabular}{llll}
\hline & IMC=25 & IMC $<25$ & $\mathbf{p}$ \\
$\mathbf{N}$ & $\mathbf{1 0}$ & $\mathbf{8}$ & \\
\hline Idade (anos) & $55.5 \pm 11.5$ & $64.1 \pm 4.6$ & 0.06 \\
LN/cadaver & $5.5 \pm 4.4$ & $4.5 \pm 2.9$ & 0.59 \\
Tamanho Médio & $22 \pm 11 \mathrm{~mm}$ & $40 \pm 27 \mathrm{~mm}$ & 0.07 \\
\hline
\end{tabular}

Analisamos a distribuição radial dos linfonodos no mesorreto. Na região posterior o número e tamanho destes foram significativamente maiores quando comparados às regiões esquerda e direita $(p=0.01 \mathrm{e}$ $\mathrm{p}=0.02$ para número e tamanho, respectivamente). Esses dados são mostrados na Tabela 3.

Tabela 3. Características de acordo com localização.

\begin{tabular}{lllll}
\hline Local (todos 3 níveis) & Posterior & Lateral Direito & Lateral Esquerdo & p \\
\hline Tamanho Médio $(\mathrm{mm})$ & $54 \pm 30$ & $21 \pm 35$ & $14 \pm 16$ & 0.01 \\
LN/cadaver & $2.8 \pm 2.8$ & $0.8 \pm 0.9$ & $1.2 \pm 1.4$ & 0.02 \\
Nível (todos locais) & Proximal & Médio & Distal & p \\
Tamanho Médio (mm) & $48 \pm 42$ & $22 \pm 23$ & $19 \pm 21$ & $0.02^{*}$ \\
LN/cadaver & $2.0 \pm 1.6$ & $1.6 \pm 2.1$ & $1.2 \pm 1.9$ & 0.1 \\
\hline
\end{tabular}

${ }^{*} p=0.02$ somente para proximal versus distal; não houve diferença significante entre o nível médio e os outros níveis ( $p>0.05$ ) 
Estudando então a distribuição longitudinal dos linfonodos no mesorreto, pudemos constatar uma diferença estatisticamente significante entre o tamanho dos linfonodos dos terços proximal $(4.8 \pm 4.2$ $\mathrm{mm})$ e distal $(1.9 \pm 2.1 \mathrm{~mm})$ do reto $(p=0.02)$, o que representamos também na Tabela 3 .

\section{DISCUSSÃO}

Analisando os dados obtidos através da dissecção podemos fazer uma série de considerações relevantes. O tamanho médio dos linfonodos do mesorreto $(3 \pm 2 \mathrm{~mm})$ é bastante reduzido, o que pode ter grande impacto nos resultados anátomo-patológicos da peça cirúrgica. Apesar de poderem receber células metastáticas ${ }^{11}$, linfonodos de tamanho reduzido algumas vezes não são identificados na análise da peça, o que afeta diretamente o estadiamento do tumor.

É evidente a grande dificuldade para a identificação dos linfonodos de mesorreto devido não apenas ao seu pequeno tamanho, mas principalmente à semelhança de cor e consistência com o tecido gorduroso que os envolve. Enquanto no presente estudo encontramos uma média de 5.0 \pm 3.7 linfonodos no mesorreto, um estudo de pacientes com câncer retal ${ }^{8}$ identificou uma média de 28 linfonodos no mesorreto, o que evidencia a maior facilidade de encontrá-los quando há metástases ou inflamação.

Para aumentar o número de linfonodos identificados poderíamos utilizar algumas soluções especiais ${ }^{4}$ que facilitam a separação do tecido gorduroso que os envolve. Essa não é, no entanto, a rotina seguida pelos patologistas, devido principalmente ao maior custo e à toxicidade dessas soluções. Foi recentemente demonstrado ${ }^{7}$ que o uso de tais soluções tem impacto direto sobre o número de linfonodos identificados. Sabe-se também que pelo menos 13 ou 14 linfonodos precisam ser examinados para definir um estadiamento confiável do câncer de reto ${ }^{9,12}$, e que quanto maior o número de linfonodos analisados mais preciso é esse diagnóstico. É interessante, portanto, do ponto de vista de tratamento, que linfonodos pequenos sejam identificados; e para isso a introdução, na rotina da patologia, de soluções que facilitam a identificação destes seria um grande progresso.

A região posterior do mesorreto apresenta linfonodos mais numerosos e maiores quando comparada com as regiões esquerda e direita $(p=$ 0.02). Tal fato explica a grande queda das taxas de recidiva local com a adoção da excisão total do mesorreto, já que anteriormente, ao proceder-se a cirurgia tradicional para câncer de reto, uma parte considerável da região posterior não era retirada. Nesse sentido a violação do aspecto posterior do mesorreto pode ter implicações significantes sobre a disseminação de células tumorais devido à distribuição dos linfonodos nessa região.

Um fato de grande importância confirmado pelo presente estudo é a presença de linfonodos no terço distal do mesorreto. Enquanto nos terços proximal e médio encontramos, respectivamente, 2.0 \pm 1.6 e $1.6 \pm 2.1$ linfonodos, no terço distal foram dissecados $1.2 \pm 1.9$ linfonodos $(p=0.1)$. O número de linfonodos nos três terços do reto não apresenta, pois, diferença estatisticamente significante. Por outro lado, quando comparamos o tamanho médio dos linfonodos encontrados nos terços proximal e distal $(4.8 \pm 4.2 \mathrm{~mm}$ e $1.9 \pm 2.1 \mathrm{~mm}$, respectivamente; $\mathrm{p}=0.02$ ) encontramos diferenças estatísticamente significantes.

Esses achados nos revelam que embora significativamente menores os linfonodos estão presentes no terço distal do mesorreto. Tal fato corrobora a idéia de que a cirurgia para tratamento do câncer de reto, especialmente daqueles localizados nos terços médio e distal, passa obrigatoriamente pela dissecção e retirada do terço distal do mesorreto.

A drenagem linfática no mesorreto dificilmente ocorre no sentido crânio-caudal ${ }^{1}$, o que poderia supor ser a retirada do terço distal do mesorreto um procedimento muito agressivo e desnecessário para tratamento de tumores localizados nos terços médio e proximal. No entanto, acreditamos que, quando possível, qualquer possibilidade de disseminação de células tumorais deve ser evitada.

Dessa forma, a excisão total do mesorreto, para garantir a retirada de todos os linfonodos e reduzir ao máximo a possibilidade de disseminação linfática de células tumorais, deve obrigatoriamente incluir o terço distal do mesorreto. 
Seid VE, Perez RO, Bresciani CJC, Pereira DD, Bresciani EH, Bresciani BH. Distribution of lymph nodes - how deep is it TME necessary? Rev Med (São Paulo). 2007 abr.-jun.;86(2):101-5.

\begin{abstract}
Introduction: Standardization of TME had a great impact on decreasing local recurrence rates for the treatment of rectal cancer. However, number and distribution of lymph nodes along the mesorectum remains controversial. In order to confirm lower frequency of distal lymph nodes in the mesorectum we performed a cadaveric study. Patients and Methods: 18 fresh cadavers were included in the study. The rectum was removed along with total mesorectal excision by an abdominal median incision. The fatty tissue of the mesorectum was divided into lateral-right, posterior and lateral-left portions. These segments were subdivided into proximal to distal levels (1-3). Histological confirmation was performed after complete lymph nodes dissection. Results: Overall, the mean number and size of lymph nodes/rectum was $5.0 \pm 3.7$ and $3 \pm 2.7 \mathrm{~mm}$. There was no association between the mean number or size with gender, $\mathrm{BMI}$ or age. There was a significantly higher prevalence of posterior LN location (2.8 LN/patient) as opposed to lateral locations ( 0.8 and $1.2 \mathrm{LN} /$ patient; $\mathrm{p}=0.02)$. There was similar distribution of LN/patient between different rectal levels. Conclusions: Lymph nodes in the mesorectal tissue are predominantly small and posteriorly located. There is no decrease in the number of lymph nodes in the most distal third of the mesorectum.
\end{abstract}

KEY WORDS: Rectal neoplasms/surgery. Lymph nodes/pathology. Adenocarcinoma. Colorectal surgery/methods.

\title{
REFERÊNCIAS
}

1. Bartholdson L, Hultborn A, Hulten L, Roos B, Rosencrantz $\mathrm{M}$, Ahren $\mathrm{C}$. Lymph drainage from the upper and middle third of the rectum as demonstrated by $198 \mathrm{Au}$. Acta Radiol Ther Phys Biol. 1977;16(4):352-60.

2. Bissett IP, Fernando CC, Hough DM, Cowan BR, Chau $K Y$, Young AA, et al. Identification of the fascia propria by magnetic resonance imaging and its relevance to preoperative assessment of rectal cancer. Dis Colon Rectum. 2001;44(2):259-65.

3. Heald RJ, Husband EM, Ryall RD. The mesorectum in rectal cancer surgery-the clue to pelvic recurrence? Br J Surg. 1982;69(10):613-6.

4. Jan YJ, Huang PC, Chen JT, Ho WL. Lymph node revealing solution and traditional $10 \%$ buffered formaldehyde for detecting lymph nodes in colorectal carcinoma. Zhonghua Yi Xue Za Zhi (Taipei). 2000;63(2):131-7.

5. Murty M, Enker WE, Martz J. Current status of total mesorectal excision and autonomic nerve preservation in rectal cancer. Semin Surg Oncol. 2000;19(4):321-8.

6. Sjodahl R. The role of total mesorectal excision in rectal cancer surgery. Eur J Surg Oncol. 2001;27(5):440-1.

7. Svec A, Horak L, Novotny J, Lysy P. Re-fixation in a lymph node revealing solution is a powerful method for identifying lymph nodes in colorectal resection specimens. Eur J Surg Oncol. 2006;32(4):426-9.

8. Takahashi T, Ueno M, Azekura K, Ohta H. Lateral node dissection and total mesorectal excision for rectal cancer. Dis Colon Rectum. 2000;43(10 Suppl):S59-68.

9. Tepper JE, O'Connell MJ, Niedzwiecki D, Hollis D, Compton $\mathrm{C}$, Benson $\mathrm{AB}$, et al. Impact of number of nodes retrieved on outcome in patients with rectal cancer. J Clin Oncol. 2001;19(1):157-63.

10. Topor B, Acland R, Kolodko V, Galandiuk S. Mesorectal lymph nodes: their location and distribution within the mesorectum. Dis Colon Rectum. 2003;46(6):779-85.

11. Vorburger $S$, Metzger U. [Role of lymph nodes in rectal carcinoma]. Zentralbl Chir. 2000;125(10):852-62.

12. Wong JH, Severino R, Honnebier MB, Tom P, Namiki TS. Number of nodes examined and staging accuracy in colorectal carcinoma. J Clin Oncol. 1999;17(9):2896900. 